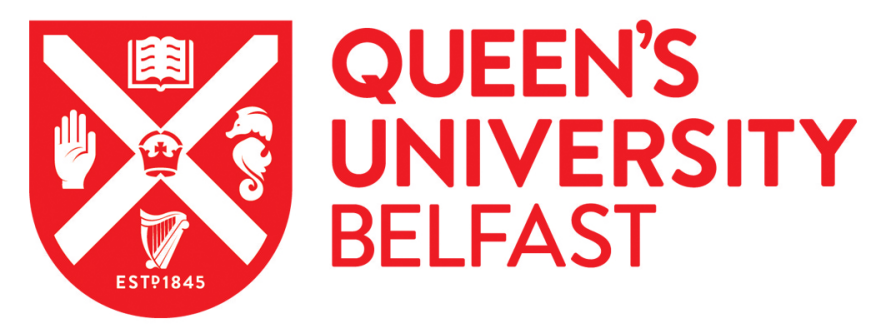

\title{
Effect of shear forces on dispersion-related properties of microcrystalline cellulose-reinforced EVOH composites for advanced
} applications

Graninger, G., Kumar, S., Garrett, G., \& Falzon, B. G. (2020). Effect of shear forces on dispersion-related properties of microcrystalline cellulose-reinforced EVOH composites for advanced applications. Composites Part A: Applied Science and Manufacturing, 139, [106103]. https://doi.org/10.1016/j.compositesa.2020.106103

Published in:

Composites Part A: Applied Science and Manufacturing

Document Version:

Peer reviewed version

Queen's University Belfast - Research Portal:

Link to publication record in Queen's University Belfast Research Portal

\section{Publisher rights}

Copyright 2020 Elsevier.

This manuscript is distributed under a Creative Commons Attribution-NonCommercial-NoDerivs License

(https://creativecommons.org/licenses/by-nc-nd/4.0/), which permits distribution and reproduction for non-commercial purposes, provided the author and source are cited.

\section{General rights}

Copyright for the publications made accessible via the Queen's University Belfast Research Portal is retained by the author(s) and / or other copyright owners and it is a condition of accessing these publications that users recognise and abide by the legal requirements associated with these rights.

\section{Take down policy}

The Research Portal is Queen's institutional repository that provides access to Queen's research output. Every effort has been made to ensure that content in the Research Portal does not infringe any person's rights, or applicable UK laws. If you discover content in the

Research Portal that you believe breaches copyright or violates any law, please contact openaccess@qub.ac.uk. 


\section{Journal Pre-proofs}

Effect of shear forces on dispersion-related properties of microcrystalline cellulose-reinforced EVOH composites for advanced applications

Georg Graninger, Sandeep Kumar, Graham Garrett, Brian G. Falzon

PII:

S1359-835X(20)30342-0

DOI: https://doi.org/10.1016/j.compositesa.2020.106103

Reference: JCOMA 106103

To appear in:

$$
\text { Composites: Part A }
$$

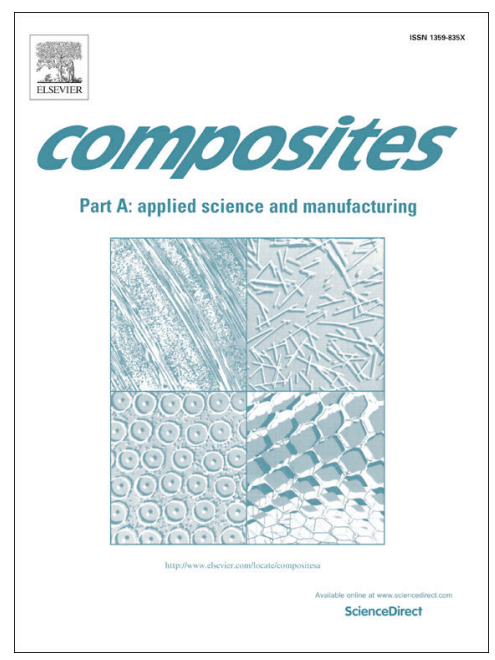

Received Date:

24 April 2020

Revised Date:

24 August 2020

Accepted Date:

27 August 2020

Please cite this article as: Graninger, G., Kumar, S., Garrett, G., Falzon, B.G., Effect of shear forces on dispersion-related properties of microcrystalline cellulose-reinforced EVOH composites for advanced applications, Composites: Part A (2020), doi: https://doi.org/10.1016/j.compositesa.2020.106103

This is a PDF file of an article that has undergone enhancements after acceptance, such as the addition of a cover page and metadata, and formatting for readability, but it is not yet the definitive version of record. This version will undergo additional copyediting, typesetting and review before it is published in its final form, but we are providing this version to give early visibility of the article. Please note that, during the production process, errors may be discovered which could affect the content, and all legal disclaimers that apply to the journal pertain.

(C) 2020 Published by Elsevier Ltd. 


\title{
Effect of shear forces on dispersion-related properties of microcrystalline cellulose- reinforced EVOH composites for advanced applications
}

\author{
Georg Graninger a, Sandeep Kumar ${ }^{a *}$, Graham Garrett ${ }^{b}$, Brian G. Falzon ${ }^{\text {a* }}$ \\ a Advanced Composites Research Group, School of Mechanical and Aerospace \\ Engineering, Queen's University Belfast, BT9 5AH, UK \\ b Polymer Processing Research Centre, School of Mechanical and Aerospace Engineering, \\ Queen's University Belfast, BT9 5AH, UK \\ Email: b.falzon@qub.ac.uk, sandeep.kumar@qub.ac.uk
}

\begin{abstract}
Recently, inexpensive and readily available bio-renewable microcrystalline cellulose (MCC) has been explored as a filler to mechanically reinforce thermoplastic matrices. Most research focuses on surface modification of MCC to improve dispersion in the polymer matrix. Herein, two screw configurations (low shear (LS) and high shear (HS)) were designed for twin-screw extrusion to investigate the effect of shear, during processing, on the dispersion of MCC particles in an ethylene-vinyl alcohol $(\mathrm{EVOH})$ matrix. The results demonstrate the significance of the high shear screw configuration on the size of MCC particles, and their in-situ fibrillation and distribution within the EVOH matrix. HS mixing of EVOH/MCC resulted in a significant increase in flexural strength and storage modulus compared to EVOH/MCC (LS) composites, similar to property improvement in $\mathrm{EVOH} /$ cellulose nanocrystal ( $\mathrm{CNC}$ ) composites at the same loading, thus providing an alternative to energy-intensive CNC in continuous melt processing without an appreciable rise in production costs.
\end{abstract}

Keywords: A. cellulose, B. mechanical properties, D. electron microscopy, E. extrusion.

\section{Introduction}

Cellulose is a biodegradable polysaccharide polymer that plays a critical role in the structure of plant cell walls in nature. In the shape of crystalline microfibrils with a $4 \mathrm{~nm}$ to $30 \mathrm{~nm}$ diameter, cellulose is embedded in matrix polysaccharides, such as hemicellulose, pectin and 
lignin. Depending on the source and their location in the primary or secondary plant cell walls, the constituents are present at percentages of up to $40 \%$ (cellulose), $20 \%$ to $40 \%$ (hemicellulose), $35 \%$ (pectin) and $10 \%$ to $25 \%$ (lignin). The combination of cellulose and matrix polysaccharides forms a strong composite network that provides strength and resilience against degradation to the plant cell wall [1-4]. The high intrinsic mechanical properties of cellulose have attracted interest from the academic and industrial research communities as an alternative reinforcement in composites which utilise artificial fibres such as glass, carbon and aramid [5].

Abundant in natural resources, several forms of cellulose can be extracted from cotton, wood, plant fibres, jute, etc., generally categorized as cellulose nanocrystals (CNC), cellulose nanofibrils (CNF), microfibrillated cellulose (MFC) and microcrystalline cellulose (MCC) using various isolation routes $[5,6,7]$. All cellulose forms share the advantages of high elastic moduli (CNC: 100 - 160 GPa [8, 9], CNF: 136 - 150 GPa [1, 10], MFC: 29 - 36 GPa [11, 12], MCC: $25 \mathrm{GPa}$ [13]) in combination with low density as well as biocompatibility, biodegradability and low cost $[5,6]$. A high number of hydroxyl groups present along the cellulose surface can lead to the formation of hydrogen bonding and allows for surface modifications [7].

Acid hydrolysis is a common and facile process to extract microcrystalline cellulose (MCC) and cellulose nanocrystals (CNC) from biomass [6, 14]. During acid hydrolysis, treatment of cellulosic fibres with mineral acids such as sulfuric acid $\left(\mathrm{H}_{2} \mathrm{SO}_{4}\right)$ causes dissolution of the amorphous domains [15]. Mild acid-catalysed hydrolysis promotes the formation of cellulose microfibril aggregates, which are highly crystalline (MCC). Application of concentrated, strong acids or an extended exposure to the hydrolysis treatment produce CNC $[16,17,18]$. The rodor whisker-like nanoparticles (length: $50-500 \mathrm{~nm}$, width: $5-20 \mathrm{~nm}$ ) possess a high aspect ratio and a high contact surface area, enabling greater interfacial interactions with surrounding matrix yielding substantial improvements in mechanical properties [6, 19]. Significant improvements in mechanical performance (Young's modulus, tensile strength) were achieved when using $\mathrm{CNC}$ as reinforcement in various polymer matrices including high density 
polyethylene (HDPE) (+29\%, +23\%) and epoxy (+23\%, +28\%) [14, 20, 21]. Zhang et al. reported a strong increase in flexural modulus (+52\%) and strength (+19\%) when combining CNC with polylactic acid (PLA) [22].

Small yields and neutralization processes limit the fabrication of CNC to amounts only suitable for lab-scale applications $[23,24,25]$. CNC can also be directly obtained via high-shear homogenization of MCC. While this post-treatment has the potential to be used in commercial productions, applying a second processing step after acid hydrolysis renders the CNC less affordable $[16,23]$. In comparison, the selling price for MCC is around $\$ 4 / \mathrm{kg}$, while the manufacturing costs for CNC alone range between $\$ 3.6-\$ 4.4 / \mathrm{kg}[24,26]$. As a result, microcrystalline cellulose (MCC), which is a readily available, highly crystalline and a cheaper alternative to $\mathrm{CNC}$, has recently received attention as a potential candidate to enhance the mechanical performance of thermoplastics [5, 13, 26-31]. MCC is commercially available in many different grades for applications such as an excipient in pharmaceuticals, emulsifier for cosmetic products and binder in food processing [5, 26, 27].

Different processes applied during the manufacture of cellulose composites are reported in literature, including solution casting, melt processing, electrospinning, resin impregnation (physical) and in-situ polymerization (chemical). In solution casting, cellulose is dispersed within the base polymer or a pre-polymer solution using water or organic solvents. Once a homogeneous mixture has been obtained via mechanical stirring or ultrasonication, the solid nanocomposite can be extracted by evaporating the solvent (casting). This allows the manufacture of composites with a good dispersion and distribution of cellulose particles in the polymer matrix $[6,32]$.

Combined with the simplicity of the method, solution casting has become the most commonly used procedure yielding cellulose composites with many attractive functions and properties, such as synergistic effects and modulated degradation rates [33, 34]. While solution casting is restricted to small subsets of polymers and laboratory-scale production of composite 
materials, continuous melt processing in extrusion has been explored in recent years as a key processing technique for high volume applications of commodity thermoplastics [32, 35].

It is expected that the production of $\mathrm{MCC} /$ thermoplastic composites via melt extrusion will immediately be available for upscaling the process for many industrial applications [36, 37]. In terms of suitability for extrusion, MCC also benefits from a higher decomposition onset (300 $\left.{ }^{\circ} \mathrm{C}\right)$ compared to $\mathrm{CNC}\left(260^{\circ} \mathrm{C}\right)[26,36]$. Aggregation due to strong hydrogen bonding between cellulose particles has been reported as the most significant drawback of melt mixing, resulting in lower available surface area, less interfacial interactions, voids, stress concentrations and hindered stress transfer between polymer matrix and MCC fibres $[1,28,30]$.

To tackle the challenges of MCC agglomeration and poor dispersion, MCC has been functionalized to improve the dispersion and compatibility with the base matrix. Recently, Li et al. mixed unmodified MCC and surface modified MCC, respectively, in a polylactic acid (PLA) matrix using a twin-screw extruder. They observed that unmodified MCC/PLA composites showed no improvement, however, modified MCC caused noticeable improvement in crystallization and mechanical properties of the composites [38]. Similarly, Dai et al. developed PLA/MCC composites by melt compounding and reported significant decrease in flexural strength (-25\%) and strain-at-break (-46\%) at 20wt.\% of MCC, but showed that addition of epoxidized citric acid (ECA) compatibilizer increased the flexural performance of PLA/MCC composites by $18 \%$ and $32 \%$, respectively, compared to unmodified PLA/MCC composites [39]. However, up to now, no study discussed how the screw design affects the degree of dispersion of MCC in a polymer matrix.

Recently, Oksman et al. found that MCC is merely an aggregate of single cellulose crystallites and it is suggested that the application of a screw configuration with additional mixing elements to introduce higher shearing could delaminate MCC into fibrillated MCC and small cellulose nanoparticles (CNP) to promote uniform dispersion and distribution in cellulose composites $[36,40,41]$. In another study, Shirazian et al. studied the effect of the different screw design configurations on the granulation of MCC [42]. To our knowledge, no such experiments seem 
to be reported for MCC/polymer composites. However, in some other studies, related to carbon nanotubes and clay-based polymer composites, it has been realised that the extent of dispersion can be greatly improved through high-shear mixing [43-45].

Inspired by the described findings and suggestions, in this work, for the first time, we study the influence of two different screw configurations on the morphological, thermal, and mechanical properties of EVOH/MCC composites at two most commonly studied loadings (5 wt. \% and 15 wt. \%) without any processing aid additives. EVOH is a versatile semicrystalline polymer used in a number of applications such as food packaging and within the automotive industry owing to its barrier properties to, for example, mitigate food aroma and fuel vapour transmission. It was chosen as a matrix because of the hydrophilicity of the vinyl alcohol component promoting compatibility with the hydroxyl groups of the cellulose, thus improving dispersion $[30,46]$. EVOH/MCC composites prepared using a high-shear screw configuration show positive improvement in flexural, tensile, dynamic mechanical and thermal properties. For a comparative study, we also developed composites of relatively high-cost cellulose nanocrystals $(\mathrm{CNC})$ with $\mathrm{EVOH}$ under the same processing conditions. Interestingly, subjected to high-shear processing, MCC/EVOH and CNC/EVOH show comparable results at 5 wt.\% loading, which indicates the effectiveness of the designed high-shear screw configuration towards MCC particles break-up and partial delamination into fibrils. It is expected that this type of study may provide a deeper understanding and further guide the development of sustainable MCC-reinforced polymer materials with consistent mechanical properties.

\section{Experiment}

\subsection{Materials}

Ethylene vinyl alcohol (EVOH), grade F101B (ethylene content of $32 \mathrm{~mol} \%$, melting temperature: $183^{\circ} \mathrm{C}$, MFR: $1.6 \mathrm{~g} / 10 \mathrm{~min}$, density $\sim 1.19 \mathrm{~g} / \mathrm{cm}^{3}$, pellets), was obtained from Kuraray Co., Ltd., Japan. Microcrystalline cellulose (MCC) (particle size $\sim 51 \mu \mathrm{m}$, freeze-dried 
powder) was purchased from Sigma-Aldrich Company Ltd., United Kingdom. Cellulose nanocrystals (CNCs) (particle size $\sim 150 \mathrm{~nm}$, freeze-dried powder) were purchased from CelluForce, Canada. Fig. 1 shows the morphology of MCC and CNC, respectively. Fig. 1a is a magnified image $(x 100)$ of the MCC, as received. At a higher magnification of $x 55,000$, individual MCC particles are shown to consist of large aggregates of CNC (Fig. 1b). Purchased freeze-dried CNC was dispersed in de-ionized water, ultrasonicated for 30 minutes and dried in a standard oven for 30 minutes prior to SEM observation. Resulting individual cellulose nanocrystals are visible at x55,000 magnification in Fig. 1c.

\subsection{Processing of cellulose composites}

\subsubsection{Preparation of materials prior to extrusion}

EVOH pellets were ground into powder in a cryogenic grinder (6850 Freezer/Mill, Rondol Technology Ltd., United Kingdom). Cryogenic grinding was performed to achieve similar particle sizes of matrix and filler to facilitate mixing and increase compatibility of cellulose particles with EVOH during post-processing. After a pre-cool time of $10 \mathrm{~min}$, the pellets were ground in ten grinding cycles of $2 \mathrm{~min}$, each at the highest frequency setting $(15 \mathrm{~Hz})$ with $3 \mathrm{~min}$ of cooling time between two cycles, respectively, to avoid melting of the material due to high friction as well as to protect the magnetic bearing from overheating. Prior to extrusion, the matrix and cellulose powder were dry-mixed at 2,500 rpm for 4 mins using a blender (Rondol Technology Ltd., United Kingdom). All materials were dried for at least $8 \mathrm{hrs}$ at $80^{\circ} \mathrm{C}$ in a standard oven.

\subsubsection{Extrusion}

The dry-mixed blends were compounded in a co-rotating $16 \mathrm{~mm}$ twin-screw extruder with an L/D ratio of 25 (HAAKE Rheomex OS PTW16, ThermoFisher SCIENTIFIC, United Kingdom). Two different screw designs were used to process all the material combinations. For comparison purposes, pristine EVOH was also processed using both screw design configurations. The extruder barrel was divided into 6 temperature zones, excluding the 
feeder. The temperature was held constant at $210^{\circ} \mathrm{C}$ from zones 2 to 6 and $200{ }^{\circ} \mathrm{C}$ in zone 1 (closest to the feeder) (Fig. 2 \& Fig. 3). The feeding section was set to $25^{\circ} \mathrm{C}$. The blended powders were fed into the extruder with a feeding rate of $10 \mathrm{~kg} / \mathrm{hr}$.

Both screw designs were modelled as dispersive screw configurations, meaning they were assembled from conveying and kneading elements. Compared to distributive configurations, with mixing and conveying elements, dispersive design leads to longer residence times and, subsequently, to a better dispersion [43]. Both screw configurations used in this study are comprised of four conveying zones and three kneading sections. All conveying feed screw elements had the same geometry (pitch, flight width, helix angle and channel depth). Kneading blocks differed in the angle of the hexagonal opening in the middle of the elements (kneading block $\varnothing$ and kneading block 90). This allowed the kneading blocks to be arranged in angles of $30^{\circ}, 60^{\circ}$ and $90^{\circ}$ with respect to each other, along the direction of extrusion. An extrusion feed screw element was placed at the end of each screw to enable a stable feed of material into the die. The geometry of the conveying elements and kneading blocks used in this study can be found in the supplementary information, Fig. S1.

The first conveying zone (feeding section) is designed to produce a stable pressure before entering the kneading sections. The three kneading sections are separated by feed screw elements in order to avoid material overstraining or degradation. The difference between the two screw configurations lies in the arrangement of kneading blocks in kneading sections 1 and 2. For screw design 1 , the respective angle between the blocks is $30^{\circ}$ or $60^{\circ}$ forward, leading to a weak mixing effect (weak active conveying effect). The respective angles between the blocks in screw design 2 are arranged as mainly $60^{\circ}$ forward and alternating $90^{\circ}$. This gives an increased mixing effect with pure mixing between $90^{\circ}$ alternating blocks. Due to the described arrangements of kneading blocks, the shear forces introduced into the material during compounding are relatively higher for screw design 2 compared to screw design 1 . Hence, screw design 1 is dubbed 'low-shear screw configuration' (LS), while screw design 2 
is called 'high-shear screw configuration' (HS). Fig. 2 shows the low-shear screw configuration, while the high-shear configuration is illustrated in Fig. 3.

According to Villmow et al., high screw speeds and low throughputs positively affect the resulting dispersion of particles [45]. The screw speed was held constant at a rather slow speed of $125 \mathrm{rpm}$ in order to avoid overworking the material and to ensure that all differences in properties could be traced back to differences in screw design or material composition only.

The throughput is indirectly proportional to the residence time of the material spent in the extruder from feeding section to die [43]. By increasing the angle between individual kneading blocks in screw design 2, the material is held longer in those sections, resulting in a higher residence time. The residence times for screw design 1 and 2 were $52 \mathrm{~s}$ and $60 \mathrm{~s}$, respectively. The extruded material was cooled down in a water bath prior to winding up.

\subsubsection{Specimen preparation}

Extruded compounds were compression moulded into specimens using a platen press (P 200 P, COLLIN Lab \& Pilot Solutions GmbH, Germany). Flash moulds with five specimen-shaped cavities were used. The extrudate was cut into roughly $70 \mathrm{~mm}$ long rods, which were then placed with the long rectangular side of the mould. After preheating the composites in the press at $210{ }^{\circ} \mathrm{C}$ for 2 mins, the spread rubbery material was collected into specimen shape using a scraper. The respective flash mould with specimen dimensions according to ISO 527 (specimen 1BA) for tensile testing, or according to ISO 178 (preferred specimen) for flexural testing, respectively, was placed on top of the heated platen and compression moulding was performed at $210{ }^{\circ} \mathrm{C}$ and $10 \mathrm{MPa}$ for 2 mins. The material and the mould were separated from the platens using polyimide film (Kapton). The material was cooled at a rate of $10^{\circ} \mathrm{C} / \mathrm{min}$ and demoulded at $50^{\circ} \mathrm{C}$. The pressure was kept constant at $10 \mathrm{MPa}$ during cooling to avoid the formation of air entrapments while the material was still in the melting state. All specimens were dried for at least $8 \mathrm{hrs}$ at $80{ }^{\circ} \mathrm{C}$ in a standard oven prior to mechanical and dynamic mechanical testing. 


\subsection{Characterization}

\subsubsection{Microscopy}

The surfaces of fractured samples were observed with two different scanning electron microscopes (SEMs), FlexSEM 1000 (Hitachi Ltd., Japan) and JEOL JSM-6500F (JEOL Ltd., Japan). In order to avoid charging, the sample surfaces were sputter-coated with gold. Scanning electron microscopy was performed to investigate differences in morphology between high-shear and low-shear compounded composites and to qualitatively evaluate the dispersion of cellulose within the EVOH matrix.

The size of MCC particles was measured using the FlexSEM software tools in order to show the effect of screw configuration on the extent of MCC particle break-up and dispersion. As described above, MCC has been found to consist of aligned whisker-shaped nanoparticles [25]. Due to the whisker-like shape of the nanoparticles, MCC itself takes the shape of an ellipsoid. In this study, the geometry of MCC ellipsoids was approximated as the $\mathrm{x}$-axis being the longest axis (semi-major axis), while the $y$ - and z-axes being shorter (semi-minor axes) and of the same length (radius). As observed, the high shear forces generated during processing cause a shear-induced separation of MCC into small fibrillated MCC particles along the $\mathrm{x}$-axis, reducing the radius (in $\mathrm{y}$ and $\mathrm{z}$ direction) of the original MCC particle. Therefore, the diameter was selected as a representative value of the particle size to give a qualitative estimate of the influence of the screw configuration on the dispersion. From three SEM images per setting, the dimensions of 15 to 20 MCC particles were measured and results were reported as average values.

\subsubsection{Fourier transform infrared analysis}

Fourier transform infrared spectroscopy (FTIR) was used to evaluate the chemical structure of the EVOH matrix and the composites. Samples were obtained from $150 \mu \mathrm{m}$ thick films and investigated using a PerkinEImer Spectrum 100 spectrometer (PerkinElmer Inc., USA). FTIR 
spectra were generated over a wavelength range of $650 \mathrm{~cm}^{-1}$ to $4000 \mathrm{~cm}^{-1}$ with a resolution of $4 \mathrm{~cm}^{-1}$, using 16 scans.

\subsubsection{Mechanical testing}

In order to investigate the influence of varying dispersion on the mechanical properties of the composites, samples were subjected to mechanical testing, i.e. flexural and tensile. Flexural (three-point bending) properties were obtained using a Zwick/Roell Z100 (ZwickRoell GmbH \& Co. KG, Germany) universal materials testing machine. Flexural tests were conducted using a three-point bending rig (ISO 178) at a crosshead speed of $2 \mathrm{~mm} / \mathrm{min}$ for flexural modulus determination and switched to $10 \mathrm{~mm} / \mathrm{min}$ to measure the yield point until failure or maximum extension. Measurements were performed using a $10 \mathrm{kN}$ load cell. Five specimens per setting with dimensions of $80 \times 10 \times 4 \mathrm{~mm}$ (preferred specimen type according to ISO 178) were tested. Tensile tests were performed as per ISO 527 using a Lloyd LS5 Advanced Material Testing System (Ametek, Inc., USA) with a $5 \mathrm{kN}$ load cell. As suggested in the standard, for the measurement of the tensile modulus, a test speed corresponding to a strain rate of $1 \% / \mathrm{min}$ $(0.25 \mathrm{~mm} / \mathrm{min})$ was chosen. After modulus determination, the test speed was changed to $5 \mathrm{~mm} / \mathrm{min}$ to measure the yield point until failure or maximum extension. An extensometer was used to determine the true sample strain. For each setting, five specimens with a gauge length of $25 \mathrm{~mm}$ and a cross-section of $5 \times 3 \mathrm{~mm}$ (ISO 527 - specimen 1BA) were subjected to tensile loading. All tests were carried out at room temperature.

\subsubsection{Differential scanning calorimetry}

Differential scanning calorimetry (DSC) was performed using a PerkinElmer Pyris 6 calorimeter (PerkinElmer Inc., USA) to determine the crystallization parameters (degree of crystallinity, melt and crystallization temperature and glass transition) in dependence of the screw configuration. The measurement consisted of two heating and one cooling cycle in a temperature range from $30{ }^{\circ} \mathrm{C}$ to $250{ }^{\circ} \mathrm{C}$ and with an isothermal step at $250{ }^{\circ} \mathrm{C}$ for $3 \mathrm{~min}$. The heating rate was $10^{\circ} \mathrm{C} / \mathrm{min}$ and samples weighed $7.3^{+/-1} \mathrm{mg}$. Calculating the area under the 
melting peak in the second heating cycle, the degree of crystallinity was evaluated using 128.1 $\mathrm{J} / \mathrm{g}$ as the heat of fusion for $100 \%$ crystalline $\mathrm{EVOH}$ [47].

\subsubsection{Dynamic mechanical thermal analysis}

Dynamic mechanical thermal analysis (DMTA) was conducted using a Tritec 2000 DMA (Triton Technology Ltd., United Kingdom) to characterise the effect of low- and high-shear processing on the thermomechanical viscoelastic performance of the composites. Measurements were performed in single-cantilever bending mode at a constant frequency of $1 \mathrm{~Hz}$, a displacement of $0.05 \mathrm{~mm}$, a heating rate of $2 \mathrm{~K} / \mathrm{min}$, a temperature range from $30^{\circ} \mathrm{C}$ to $150^{\circ} \mathrm{C}$, and a gap distance of $20 \mathrm{~mm}$.

\subsubsection{Thermogravimetric analysis}

A TGA/SDTA851e (Mettler Toledo, USA) was used to perform thermogravimetric analysis (TGA) of EVOH and MCC/EVOH composite samples. The goal was to determine the effect of different cellulose types ( $\mathrm{MCC} \& \mathrm{CNC}$ ) on the thermal stability of the $\mathrm{EVOH} /$ cellulose composites. The measurements were performed in an $\mathrm{O}_{2}$ environment at a temperature range from $30^{\circ} \mathrm{C}$ to $600{ }^{\circ} \mathrm{C}$ and heating rate of $10^{\circ} \mathrm{C} / \mathrm{min}$.

\subsubsection{Statistical analysis}

All measurements were reported as mean +/- standard deviation (SD) with a confidence level of $95 \%$. Differences were statistically tested against a null hypothesis of no difference between samples using a two-sample t-test (two-tailed) with equal variance not assumed. A p-value $<0.05$ was considered to be statistically significant. Prior to performing the t-test, outliers were determined using the Interquartile Range Method. Outliers due to failure outside the gauge length or flaws in the specimen which leads to premature failure were not included in the calculation of average values. Also, a Kolmogorov-Smirnov Goodness of Fit Test was applied to check whether the data is normal distributed, which is a pre-condition for using the t-test method. 


\section{Results and discussion}

\subsection{Morphological studies}

SEM observations of the fractured sample surfaces were performed to reveal the extent of dispersion of cellulose particles in the EVOH matrix at $x 100$ and x500 magnification for two screw design configurations (LS \& HS). Fig. 4 illustrates that the MCC particles are well distributed within the EVOH matrix. It is clearly visible that MCC particles are partially covered by the matrix, which indicates possible interfacial interactions between matrix and MCC fibre surfaces [6]. The influence of the different screw configurations is evident from the given SEM images for two magnifications. At x100 magnification (low magnification, Fig. 4a), processing with screw design 1 (low-shear) leads to agglomerated particles being randomly distributed with few smaller particles elsewhere. Fig. 4b shows a particle agglomerate isolated in the observed area. In contrast, screw design 2 (high-shear, Fig. 4c) results in smaller-sized MCC particles and an increased number of particles. This is also visible at $x 500$ magnification, where an improved distribution of particles can be observed when using screw design 2 (Fig. $4 d)$.

The results for particle size for both weight contents and screw designs at $\times 100$ are summarized in the supplementary information, with values for a qualitative comparison in Table S1. Presented average values are based on measurements taken at three random spots across the fracture surface of specimens. Fig. S2 (supplementary information) shows histograms and cumulative plots for the corresponding settings. The plots indicate that particle size between particles generally decrease, with narrower distributions when using the high shear screw configuration. For screw design 1 (LS), MCC particles possess a similar size in the composite for both weight contents. Compounding with screw design 2 (HS) causes a reduction in particle size for both weight contents. A larger reduction can be achieved for 5 wt.\%. This is believed to be due to satiation of the matrix with filler particles, which can promote particle-particle interaction [28]. It is therefore argued that a better dispersion with smaller particles can be achieved at 5 wt. \% compared to 15 wt. \% using screw design 2 . 
Fig. 5 and Fig. S3 (supplementary information) reveal high magnification images of the EVOH/MCC fractures surfaces at different wt.\% for LS and HS configurations. Composites containing 5.0 wt. \% MCC prepared by LS configuration show presence of large agglomerated MCC, but interestingly, images of composites prepared under HS configuration show smallsized, fibrillated MCC as well as many randomly distributed white dots, representing exposed nanocellulose particles (CNP), indicated by white arrows. It seems that high shear stresses, generated during high shear mixing (HS screw configuration with maximum angles between individual kneading blocks) and strong interactions between polar EVOH/MCC overcome the strong intermolecular hydrogen bonds between crystalline cellulose domains. This causes fibrillation of MCC (formation of sub-micron fibrils) and separation of individual CNP particles from fibrillated MCC. Fig. S3 shows that composites containing 15 wt. $\%$ of MCC (made via LS), already contain individual CNP particles along with large MCC. This indicates that at high content the friction of MCC agglomerates against each other renders the formation of small CNP particles within the matrix. However, at HS mixing, the size of MCC agglomerates is decreased and the separation of individual CNP from MCC becomes more dominant (as indicated by white arrows).

Interestingly, the CNP formed in MCC/EVOH composites share the same shape and features as CNC dispersed in 5.0wt\% CNC/EVOH (LS \& HS) composite as confirmed by Fig. 5c/d and Fig. 6. It is important to mention that we did not see any noticeable change in degree of dispersion for CNC/EVOH (LS \& HS), which indicates that nano-size CNC readily dispersed in $\mathrm{EVOH}$ due to the strong CNC-EVOH interactions even at LS. However, the screw design displayed a distinguishable effect on the size of MCC agglomerates and the in-situ formation of CNP from MCC. Interaction between matrix and cellulose particles was confirmed via FTIR analysis, where a shift of EVOH peaks to higher wavenumbers was found (see supplementary data \& Fig. S4).

\subsection{Mechanical properties}


Fig. 7 shows the mechanical properties of EVOH composites as a function of screw design at loading of 5.0 and $15.0 \mathrm{wt} . \% \mathrm{MCC}$ as well as typical flexural stress-strain curves.

The flexural modulus of pristine EVOH was measured as $3.60+/-0.07 \mathrm{GPa}$ (LS) and $3.54+/$ $0.04 \mathrm{GPa}(\mathrm{HS})$, respectively, indicating that the screw configuration has no significant influence on pristine EVOH properties. The introduction of $5 \mathrm{wt} . \%$ and $15 \mathrm{wt} . \%$ of MCC into the EVOH with low-shear (LS) screw configuration led to an increase in the flexural modulus and a decrease in the flexural strength and strain-at-break. The flexural modulus of the composites increased significantly at $15 \mathrm{wt} . \% \mathrm{MCC}(+18.1 \%)$ content. This behaviour is expected as cellulose particles, being stiffer than the matrix, add stiffness to the composite $[28,31,51]$. However, mean values of flexural strength of $5 \mathrm{wt} \%$ and $15 \mathrm{wt} . \% \mathrm{MCC}-\mathrm{EVOH}$ composites (LS) were lower compared to pristine EVOH (-16.8\% and $-9.7 \%)$. In addition, we also observed a significant decline in the strain-at-break [52].

Interestingly, compared to $5 \mathrm{wt} . \%$ of MCC (LS), we see an improvement in the strength (still lower than control EVOH) and modulus at $15.0 \mathrm{wt}$ \% of MCC (LS), which could be attributed to the formation of individual CNP in the matrix along with MCC agglomerates (as discussed and shown in Fig. S3a). An increased flexural modulus combined with a decreased flexural strength and strain-at-break, as obtained in this study using the LS screw configuration, has also been reported for various MCC/polymer-based composites $[39,53]$. For such findings, the major reason was ascribed to the presence of agglomerates that limit the compatibility and create crack-initiation sites that render the composite brittle. It appears that fabrication of the composites via a batch mixer (roller blades) and a conical twin-screw extruder could not prevent the formation of agglomerates. This being said, the formation of a considerable amount of larger agglomerates could be the reason for the decrease in strength and strain-atbreak, but none of the studies report the possibility of alternative screw design configurations to reduce the size of MCC agglomerates.

When applying the high-shear (HS) screw design, the flexural modulus of EVOH/MCC composites showed better improvement compared to control EVOH and EVOH/MCC (LS) at 
the same MCC content. Incorporation of $5 \mathrm{wt} . \%$ and $15 \mathrm{wt} . \%$ of MCC showed a noticeable increase in the flexural modulus, $9.0 \%$ and $22.5 \%$, respectively, compared to EVOH. Also, with HS configuration, flexural strength was maintained at $5 \mathrm{wt} . \%$ and $15 \mathrm{wt} . \%$. A significant increase in flexural strength for $\mathrm{EVOH} / \mathrm{MCC}$ at $5 \mathrm{wt}$ \% was found compared to $\mathrm{EVOH} / \mathrm{MCC}$ (LS) $(20.5 \%$ higher). However, at higher MCC content (15 wt.\%), EVOH/MCC (HS) showed a slight decrease in flexural strength, but still higher than EVOH/MCC (LS). At the same MCC concentration, enhancement of the flexural strength for $\mathrm{EVOH} / \mathrm{MCC}$ is symptomatic of the dominant screw design effect over the concentration effect.

Equally significant, at HS configuration, the strain-at-break values are recovered to the level of control EVOH. At 5.0 wt. \% of MCC loading, EVOH/MCC composites exhibit the same strainat-break as compared with the control EVOH. These findings are unique compared to those reported in the literature for different MCC-based polymer composites, which report significant reductions in strain-at-break. It is also extensively reported in literature that improvement in strength and strain-at-break is critically dependent on the dispersion and the amount of interfacial interactions. In the present case, it seems that the application of a large number of high-angle kneading elements resulted in the generation of high stresses, which overcame the strong Van-der-Waals interaction between the MCC agglomerates. As observed from the SEM images, agglomerates are broken up and high shear forces lead to the formation of small-fibrillated MCC particles as well as strongly-bonded well-dispersed CNP particles within the EVOH matrix. The better improvement in the flexural modulus for $\mathrm{EVOH} / \mathrm{MCC}(\mathrm{HS})$ seems to be controlled by the inherent high stiffness of formed CNP and the enhanced stiffness of the interfaces. Uniform dispersion of CNP and small-fibrillated MCC improve interfacial interactions, which facilitate the stress transfer to boost the strength. Apart from the formation of strongly-bonded CNP within the EVOH matrix through HS configuration, energy dissipation/strain energy release due to sliding of the MCC fibrils in the interface regions can also be considered as a possible contributing factor towards retaining the strain-at-break. When adding 5 wt.\% CNCs, we observed similar noticeable improvement in flexural modulus 
and strength, without any change in strain-at-break (\%) at both LS and HS screw configurations, which means that CNCs are readily dispersed in EVOH even at LS configuration. Fig. 6 confirms the highly intimate contact between stiff CNC and matrix resulting from the strong hydrogen bonding between polar EVOH and the CNCs. From these observations, it seems that the formation of CNP in EVOH/MCC composites (at HS) contributed significantly to flexural property enhancement. In summary, flexural tests show that the EVOH/MCC (HS) possess both higher flexural strength and modulus, together with acceptable strain-to-failure properties compared to control EVOH. Most importantly, the flexural performance of MCC (5 wt.\%) and CNC (5 wt.\%.) composites at high shear (HS) are comparable. It can, therefore, be argued that by using MCC particles and applying high shear during processing, similar properties can be gained as when using CNC particles. This removes the need to use costly and energy-intensive nano-fillers, which are potentially hazardous to health. Consequently, this study provides insight into the use of readily available cellulose fillers in the continuous melt processing of cellulose composites. For tensile properties showing an increase of $21 \%$ in tensile modulus at $15 \mathrm{wt} \% \mathrm{MCC}$ and maintaining the tensile strength at 5 wt.\% MCC compared to pristine EVOH when processed with the HS screw configuration, refer to supplementary information (Fig. S5).

In order to evaluate the thermomechanical viscoelastic performance of EVOH/MCC composites in dynamic bending mode, we performed dynamic mechanical thermal analysis (DMTA). This technique allows the determination of the viscoelastic response of materials over a broad temperature range and is strongly sensitive to the morphology and structure of the composite. The trends of the storage moduli E' of the control EVOH and the EVOH/MCC composites at different MCC wt.\% for two screw design configurations (LS and HS) are presented in Fig. 8. Fig. S6 (supplementary information) contains the representative curves.

At 5 wt. \% and 15 wt.\% MCC, the storage modulus (E') of EVOH/MCC composites made using the LS screw configuration increased from $2.24+/-0.03 \mathrm{GPa}$ (control EVOH) to a modest 2.41 +/- $0.03 \mathrm{GPa}$ and $2.53+/-0.00 \mathrm{GPa}$, as can be seen in Fig. 8a. Hence, the improvements are 
$8 \%$ and $13 \%$ with respect to control EVOH. However, for EVOH/MCC made using the HS screw configuration, the potential of storage modulus (E') improvement is noteworthy. At 5 wt.\% and 15 wt.\%, storage moduli ( $\left.E^{\prime}\right)$ increased from $2.17+/-0.16 \mathrm{GPa}$ (control EVOH) to $2.55+/-0.08 \mathrm{GPa}$ and $2.75+/-0.00 \mathrm{GPa}$, respectively, which is $18 \%$ and $27 \%$ higher than control EVOH. The improvement at a small loading of $5 \mathrm{wt}$ \% for EVOH/MCC (HS) compared to $E V O H / M C C ~(L S)$ verifies the extensive effect of strong reinforcement. It seems that the formation of fibrillated MCC and CNP particles induced a synergistic effect, which enables efficient stress transfer at the interface $[29,55]$. Shumigin et al. suggested an improved energy storage mechanism at the interphase due to longer relaxation times of a well-dispersed matrixfiller system [55]. The much lower enhancements for EVOH/MCC (LS) could be attributed to exacerbation of agglomerates of MCC. [29,56]. Kiziltas et al. achieved an increase of $20 \%$ in storage modulus for a MCC weight content of $20 \mathrm{wt} . \%$ in Nylon $6-\mathrm{MCC}$ composites at $30^{\circ} \mathrm{C}$. This was attributed to a non-sufficient distribution of stress through the composite, but in the present study improvements were achieved at $5 \mathrm{wt} . \%$ and $15 \mathrm{wt} . \% \mathrm{MCC}$ by the application of the high-shear screw design [26]. Even more pronounced improvements are observed in the rubbery state above $\mathrm{T}_{\mathrm{g}}\left(\mathrm{E}^{\prime}\right.$ at $\left.110^{\circ} \mathrm{C}\right)$ for $\mathrm{EVOH} / \mathrm{MCC}(\mathrm{HS})$ composites compared to $\mathrm{EVOH} / \mathrm{MCC}$ (LS) at the same MCC content, as shown in Fig. 8b. The storage modulus of EVOH/MCC (HS) in the rubbery state with 5 wt.\% and 15 wt.\% MCC increased by $23 \%$ and $44 \%$, respectively. The rubbery plateau is generally considered as an indication of the degree of interactions between matrix and filler and large confinement of polymeric chains on the surface of fillers. The storage modulus improvement above $T_{g}$ indicates that the high surface area of submicron fibrils of fibrillated MCC and the formed CNP have significant influence on the chain mobility, and, hence, confined EVOH molecular chains needed more heat to cause the segmental motion.

\subsection{Thermal studies}

Differential scanning calorimetry (DSC) was used to investigate the influence of the two different screw configurations (LS and HS) on the melting and crystallization behaviour of the 
$\mathrm{EVOH} / \mathrm{MCC}$ and $\mathrm{EVOH} / \mathrm{CNC}$ composites. Information on the crystallization temperature $\left(\mathrm{T}_{\mathrm{c}}\right)$ and the crystallinity $\left(X_{c}\right)$ of the samples, and the corresponding DSC thermograms are summarized in the supplementary information (Table S2, Fig. S7). There, it is evident that MCC and $\mathrm{CNC}$ have no influence on the glass transition temperature and on the melting point of EVOH composites, which indicates that EVOH structural integrity is intact. From Fig. 9, it can be seen that the degree of crystallinity of EVOH/MCC (LS) composites remained the same at $5 \mathrm{wt} . \%$, and decreased by $10 \%$ at $15 \mathrm{wt} . \%$ of MCC. Similar results have also been reported in earlier studies on MCC-based composites with other polymers [38, 57].

While the crystallization temperature showed a slight increase for all composites $\left(+3.5^{\circ} \mathrm{C}\right)$ because of the well-known nucleating effect of crystalline fillers, the crystallinity is primarily dependent on the extent of dispersion. Consequently, for the EVOH/MCC (HS) composites, the degree of crystallinity shows a positive improvement at 5 wt. $\%$ of MCC (10 \% and $7 \%$ increase) compared to control EVOH and EVOH/MCC (LS). This improvement in crystallinity could be due to the fact that the large MCC particles turned into small, fibrillated MCC as well as CNP dispersed within the EVOH matrix. This claim is supported by the SEM studies on the fracture surfaces of EVOH/MCC (HS), as shown in Fig. 5c \& d. In EVOH/MCC (HS) composites, the small, fibrillated MCC and CNP are expected to provide a high surface area for efficient nucleation. The efficiency of a nucleating agent depends on the quality of the dispersion and the distribution of the particles. In our case, it is also plausible that the coexistence of micro- and nano- cellulose particles contributed to the EVOH crystallization properties. Li et al. also observed a similar increase in crystallinity in melt processed PLA/MCC composites (by $11.6 \%$ ) at 5 wt.\% MCC, but through surface modification of MCC [38]. This interesting contrast between crystallization properties of $\mathrm{EVOH}, \mathrm{EVOH} / \mathrm{MCC}$ (LS), and $\mathrm{EVOH} / \mathrm{MCC}(\mathrm{HS})$ was only observed at the low loading of $5 \mathrm{wt} . \% \mathrm{MCC}$. At the higher loading of 15 wt. $\%$ MCC, for HS shear configuration, the crystallinity increased by $5 \%$ compared to $\mathrm{EVOH} / \mathrm{MCC}$ (LS). However, the limited crystallization performance at $15 \mathrm{wt} \% \mathrm{MCC}$ can be explained by the effect of the relatively non-uniform dispersion of MCC in the EVOH matrix 
with increasing MCC content. The addition of CNC seems to have a positive effect on the crystallization of EVOH at both screw design configurations, and a higher improvement can be seen for EVOH/MCC (HS) at 5 wt. \% CNC compared to pristine EVOH (+12.4 \%). This can be attributed to the improved dispersion of CNC under high shear. Of note is the crystallization performance of $\mathrm{EVOH} / \mathrm{CNC}(\mathrm{HS})$ and $\mathrm{EVOH} / \mathrm{MCC}(\mathrm{HS})$, comparable at the same weight content. This indicates that the formation of CNP during high shear mixing contributed to the crystallization, by providing sufficient surface area for EVOH crystals to grow from melt state. In addition, we found that the thermal stability of the composites is not affected by the incorporation of cellulose into EVOH as discussed in the supplementary information (Fig. S8).

\section{Conclusion}

This work presented the significant effect of screw configuration on the size of MCC particles, MCC fibrillation and the in-situ formation of cellulose nanoparticles (CNP) within the EVOH matrix, which govern the mechanical and thermal properties of the composites. A microscopy study (SEM) revealed that the high shear (HS) screw configuration significantly reduced the MCC particle size and formed well-separated CNP dispersed within the EVOH matrix. At a lower loading of MCC ( $5 \mathrm{wt} . \%)$, the flexural and dynamic mechanical properties of EVOH/MCC composites were significantly influenced by the screw design configuration. For example, EVOH/MCC (HS) composites showed a $10 \% / 7 \%$ increase in crystallinity compared to control EVOH and the EVOH/MCC composites made by low shear (LS) screw configuration at $5 \mathrm{wt} . \%$ MCC. With the HS screw configuration, the trend of flexural strength and strain-atbreak improvement reversed from a negative to a positive change at $5 \mathrm{wt} . \% \mathrm{MCC}$. At $5 \mathrm{wt} . \%$ and 15 wt.\% MCC, EVOH/MCC (HS) showed more than twice the improvement in storage modulus ( $\mathrm{E}^{\prime}$ ) compared to EVOH/MCC (LS). The noteworthy improvement at a small loading of $5 \mathrm{wt} . \%$ for $\mathrm{EVOH} / \mathrm{MCC}$ (HS) compared to EVOH/MCC (LS) verifies the extensive effect of the screw design configuration. It seems that the formation of fibrillated MCC and CNP particles through the HS screw configuration induced a synergistic effect, which enables

efficient stress transfer and improved energy storage mechanism at the interphase. A 
comparison revealed that improvements due to the incorporation of MCC particles were not significantly different from CNC composites at the same loading. As a result, composites manufactured from MCC particles in a high shear environment can provide a cost-efficient, safe method to achieve high performance composites without the use of compatibilizers or lubricants using continuous melt processing methods established in industry.

\section{Acknowledgement}

The authors gratefully acknowledge the funding of this research by the Department for the Economy (DfE) (Northern Ireland, United Kingdom). Further gratitude is expressed to the Polymer Processing Research Centre (PPRC) at Queen's University Belfast (QUB) and to Sungkwon Yoon for their continued support, beneficial discussion and scientific input.

\section{Conflict of interest}

The authors declare no competing financial interest. 


\section{References}

[1] Ansari F, Berglund LA. Toward Semistructural Cellulose Nanocomposites: The Need for Scalable Processing and Interface Tailoring. Biomacromolecules 2018;19:2341-2350.

[2] Sticklen MB. Plant genetic engineering for biofuel production: towards affordable cellulosic ethanol. Nature Reviews Genetics 2008;9:433-443.

[3] Abramson M, Shoseyov O, Shani Z. Plant cell wall reconstruction toward improved lignocellulosic production and processability. Plant Science 2010;178:61-72.

[4] Cosgrove DJ. Growth of the plant cell wall. Nature Reviews Molecular Cell Biology $2005 ; 6: 850-861$.

[5] Trache D, Hussin MH, Chuin CTH, Sabar S, Fazita MRN, Taiwo OFA, Hassan TM, Haafiz MKM. Microcrystalline cellulose: Isolation, characterization and bio-composites application-A review. International Journal of Biological Macromolecules 2016;93:789-804.

[6] Mondal S. Review on Nanocellulose Polymer Nanocomposites. Polymer Plastics Technology and Engineering 2018;57(13):1377-1391.

[7] Xu X, Liu F, Jiang L, Zhu JY, Haagenson D, Wiesenborn DP. Cellulose Nanocrystals vs. Cellulose Nanofibrils: A Comparative Study on Their Microstructures and Effects as Polymer Reinforcing Agents. ACS Applied Materials \& Interfaces 2013;5:2999-3009.

[8] Eichhorn SJ, Dufresne A, Aranguren M, Marcovich NE, Capadona JR, Rowan SJ, Weder C, Thielemans W, Roman M, Renneckar S, Gindl W, Veigel S, Keckes J, Yano H, Abe K, Nogi M, Nakagaito AN, Mangalam A, Simonsen J, Benight AS, Bismarck A, Berglund LA, Peijs T. Review: current international research into cellulose nanofibers and nanocomposites. Journal of Material Science 2010;45:1-33.

[9] Šturcová A, Davies GR, Eichhorn SJ. Elastic Modulus and Stress-Transfer Properties of Tunicate Cellulose Whiskers. Biomacromolecules 2005;6:1055-1061. 
[10] Iwamoto S, Kai W, Isogai A, Iwata T. Elastic Modulus of Single Cellulose Microfibrils from Tunicate Measured by Atomic Force Microscopy. Biomacromolecules 2009;10(9):25712576.

[11] Tanpichai S, Quero F, Nogi M, Yano H, Young RJ, Lindström T, Sampson WW, Eichhorn SJ. Effective Young's Modulus of Bacterial and Microfibrillated Cellulose Fibrils in Fibrous Networks. Biomacromolecules 2012;13:1340-1349.

[12] Aulin C, Gällstedt M, Lindström T. Oxygen and oil barrier properties of microfibrillated cellulose films and coatings. Cellulose 2010;17:559-574.

[13] Eichhorn SJ, Young RJ. The Young's modulus of a microcrystalline cellulose. Cellulose 2001;8:197-207.

[14] Miao C, Hamad WY. Critical insights into the reinforcement potential of cellulose nanocrystals in polymer nanocomposites. Current Opinion in Solid State \& Materials Science 2019;23(4):1-17.

[15] Dufresne, A. Cellulose nanomaterial reinforced polymer nanocomposites. Current Opinion in Colloid \& Interface Science 2017;29:1-8.

[16] Buffiere J, Balogh-Michels Z, Borrega M, Geiger T, Zimmermann T, Sixta H. The chemical-free production of nanocelluloses from microcrystalline cellulose and their use as Pickering emulsion stabilizer. Carbohydrate Polymers 2017;178:48-56.

[17] Beck-Candanedo S, Roman M, Gray DG. Effect of Reaction Conditions on the Properties and Behavior of Wood Cellulose Nanocrystal Suspensions. Biomacromolecules 2005;5:1048-1054

[18] Dos Santos FA, Iulianelli GCV, Tavares MIB. Effect of microcrystalline and nanocrystals cellulose fillers in materials based on PLA matrix. Polymer Testing 2017;61:280288 
[19] Shrestha S, Montes F, Schueneman GT, Snyder JF, Youngblood JP. Effects of aspect ratio and crystal orientation of cellulose nanocrystals on properties of poly(vinyl alcohol) composite fibers. Composites Science and Technology 2018;167:482-488.

[20] Inai NH, Lewandowska AE, Ghita OR, Eichhorn SJ. Interfaces in polyethylene oxide modified cellulose nanocrystal - polyethylene matrix composites. Composites Science and Technology 2018;154:128-135.

[21] Peng SX, Shrestha S, Yoo Y, Youngblood JP. Enhanced dispersion and properties of a two-component epoxy nanocomposite using surface modified cellulose nanocrystals. Polymer 2017;112:359-368.

[22] Zhang Y, Cui L, Xu H, Feng X, Wang B, Pukánsky B, Mao Z, Sui X. Poly(lactic acid)/cellulose nanocrystal composites via the Pickering emulsion approach: Rheological, thermal and mechanical properties. International Journal of Biological Macromolecules, 2019;137:197-204.

[23] Bandera D, Sapkota J, Josset S, Weder C, Tingaut P, Gao X, Foster EJ, Zimmermann T. Influence of mechanical treatments on the properties of cellulose nanofibers isolated from microcrystalline cellulose. Reactive \& Functional Polymers 2014;85:134-141.

[24] De Assis CA, Houtman C, Phillips R, Bilek EM (Ted), Rojas OJ, Pal L, Peresin MS, Jameel H, Gonzalez R. Conversion Economics of Forest Biomaterials: Risk and Financial Analysis of CNC Manufacturing. Biofuels, Bioproducts and Biorefining 2017;11(4):1-19.

[25] Bondeson D, Mathew A, Oksman K. Optimization of the isolation of nanocrystals from microcrystalline cellulose by acid hydrolysis. Cellulose 2006;13:171-180.

[26] Kiziltas A, Gardner DJ, Han Y, Yang H-S. Dynamic mechanical behavior and thermal properties of microcrystalline cellulose (MCC)-filled nylon 6 composites. Thermochimica Acta 2011;519:38-43. 
[27] Podczeck F, Al-Muti E. The tensile strength of bilayered tablets made from different grades of microcrystalline cellulose. European Journal of Pharmaceutical Sciences $2010 ; 41: 483-488$.

[28] Kiziltas A, Gardner DJ, Han Y, Yang H-S. Mechanical Properties of Microcrystalline Cellulose (MCC) Filled Engineering Thermoplastic Composites. Journal of Polymers and the Environment 2014;22(3):365-372.

[29] Kiziltas A, Nazari B, Gardner DJ, Bousfield DW. Polyamide 6-Cellulose Composites: Effect of Cellulose Composition on Melt Rheology and Crystallization Behavior. Polymer Engineering and Science 2014;54(4):739-746.

[30] Mathew AP, Oksman K, Sain M. Mechanical Properties of Biodegradable Composites from Poly Lactic Acid (PLA) and Microcrystalline Cellulose (MCC). Journal of Applied Polymer Science 2005;97:2014-2025.

[31] Ashori A, Nourbakhsh A. Performance properties of microcrystalline cellulose as a reinforcing agent in wood plastic composites. Composites Part B: Engineering 2010;41:578581.

[32] Oksman K, Aitomäki Y, Mathew AP, Siqueira G, Zhou Q, Butylina S, Tanpichai S, Zhou $\mathrm{X}$, Hooshmand S. Review of the recent developments in cellulose nanocomposite processing. Composites: Part A 2016;83:2-18.

[33] Zhu J, Chen Y, Yu H-Y, Guan Y, Zhou Y, Yang X, Zou Z-Y, Tam KC. Comprehensive Insight into Degradation Mechanism of Green Biopolyester Nanocomposites Using Functionalized Cellulose Nanocrystals. ACS Sustainable Chem. Eng. 2019;7:15537-15547.

[34] Li F, Yu H-Y, Wang Y-Y, Zhou Y, Zhang H, Yao J-M, Abdalkarim SYH, Tam KC. Natural Biodegradable Poly(3-hydroxybutyrate-co-3-hydroxyvalerate) Nanocomposites with Multifunctional Cellulose Nanocrystals/Graphene Oxide Hybrids for High-Performance Food Packaging. J. Agric. Food Chem. 2019;67:10954-10967. 
[35] Sapkota J, Kumar S, Weder C, Foster EJ. Influence of Processing Conditions on Properties of Poly (Vinyl acetate)/Cellulose Nanocrystal Nanocomposites. Macromol. Mater. Eng. 2015;300:562-571.

[36] Oksman K, Mathew AP, Bondeson D, Kvien I. Manufacturing process of cellulose whiskers/polylactic acid nanocomposites. Composites Science and Technology 2006;66:2776-2784.

[37] Ray D, Sain S. In situ processing of cellulose nanocomposites. Composites Part A: Applied Science and Manufacturing 2016;83:19-37.

[38] Li H, Cao Z, Wu D, Tao G, Zhong W, Zhu H, Qiu P, Liu C. Crystallisation, mechanical properties and rheological behaviour of PLA composites reinforced by surface modified microcrystalline cellulose. Macromolecular Engineering 2016;45(4):181-187.

[39] Dai X, Xiong Z, Ma S, Li C, Wang J, Na H, Zhu J. Fabricating Highly Reactive Biobased Compatibilizers of Epoxidized Citric Acid To Improve the Flexural Properties of Polylactide/Microcrystalline Cellulose Blends. Industrial \& Engineering Chemistry Research $2015 ; 54: 3806-3812$

[40] Bondeson D, Oksman K. Polylactic acid/cellulose whisker nanocomposites modified by polyvinyl alcohol. Composites Part A: Applied Science and Manufacturing 2007;38:24862492

[41] Hietala M, Mathew AP, Oksman K. Bionanocomposites of thermoplastic starch and cellulose nanofibers manufactured using twin-screw extrusion. European Polymer Journal 2013;49:950-956.

[42] Shirazian S, Zeglinski J, Darwish S, Kuhs M, Albadarin AB, Croker DM and Walker GM. Continuous twin screw wet granulation: The combined effect of process parameters on residence time, particle size, and granule morphology. Journal of Drug Delivery Science and Technology 2018;48:319-327. 
[43] Mayoral B, Garrett G, McNally T. Influence of Screw Profile Employed During Melt Mixing on the Micro-scale Dispersion of MWCNTs in Poly(propylene). Macromolecular Materials and Engineering 2013;299:748-756.

[44] Lertwimolnun W, Vergnes B. Influence of screw profile and extrusion conditions on the microstructure of polypropylene/organoclay nanocomposites. Polymer 2007;47(12):21002109.

[45] Villmow T, Kretzschmar B, Pötschke P. Influence of screw configuration, residence time, and specific mechanical energy in twin-screw extrusion of polycaprolactone/multi-walled carbon nanotube composites. Composites Science and Technology 2010;70:2045-2055.

[46] Rosa MR, Chiou B, Medeiros ES, Wood DF, Mattoso LHC, Orts WJ, Imam SH. Biodegradable Composites Based on Starch/EVOH/Glycerol Blends and Coconut Fibers. Journal of Applied Polymer Science 2009;111:612-618.

[47] Kim SW, Choi HM. Enhancement of thermal, mechanical, and barrier properties of ethylene vinyl alcohol copolymer by incorporation of graphene nanosheets: effect of functionalization of graphene oxide. High Performance Polymers 2015;27(6):694-704.

[48] Xu D, Lu J, Yan S, Xiao R. Aminated EVOH nanofiber membranes for $\mathrm{Cr}(\mathrm{VI})$ adsorption from aqueous solution. RSC Adv. 2018;8:742-751.

[49] Sangeetha VH, Valapa RB, Nayak SK, Varghese TO. Super Toughened Renewable Poly(lactic acid) Based Ternary Blends System: Effect of Degree of Hydrolysis of Ethylene Vinyl Acetate on Impact and Thermal Properties. RSC Advances 2016;6(76):1-29.

[50] Wang YY, Yu H-Y, Yang L, Abdalkarim SYH, Chen W-L. Enhancing long-term biodegradability and UV-shielding performances of transparent polylactic acid nanocomposite films by adding cellulose nanocrystal-zinc oxide hybrids. International Journal of Biological Macromolecules 2019;141:893-905. 
[51] Salemane MG, Luyt AS. Thermal and Mechanical Properties of Polypropylene-Wood Powder Composites. Journal of Applied Polymer Science 2006;100:4173-4180.

[52] Ljunberg N, Cavaille J-Y, Heux L. Nanocomposites of isotactic polypropylene reinforced with rod-like cellulose whiskers. Polymer 2006;47(18):6285-6292.

[53] Yang H-S, Gardner DJ. Mechanical Properties of cellulose nanofibril-filled polypropylene composites. Wood and Fiber Science 2011;43(2):143-152.

[54] Yang H-S, Gardner DJ. Morphological characteristics of cellulose nanofibril-filled polypropylene composites. Wood and Fiber Science 2011;43(2):215-224.

[55] Shumigin D, Tarasova E, Krumme A, Meier P. Rheological and Mechanical Properties of Poly(lactic) Acid/Cellulose and LDPE/Cellulose Composites. Materials Science (Medžiagotyra) 2011;17(1):32-37.

[56] Seydibeyoğlu MÖ, Oksman K. Novel nanocomposites based on polyurethane and micro fibrillated cellulose. Composites Science and Technology 2008;68:908-914.

[57] Spoljaric S, Genovese A, Shanks RA. Polypropylene-microcrystalline cellulose composites with enhanced compatibility and properties. Composites Part A: Applied Science and Manufacturing 2009;40(6-7):791-799.

[58] Kiziltas A, Gardner DJ, Han Y, Yang H-S. Thermal properties of microcrystalline cellulose-filled PET-PTT blend polymer composites. Journal of Thermal Analysis and Calorimetry 2011;103:163-170. 


\section{FIGURES}
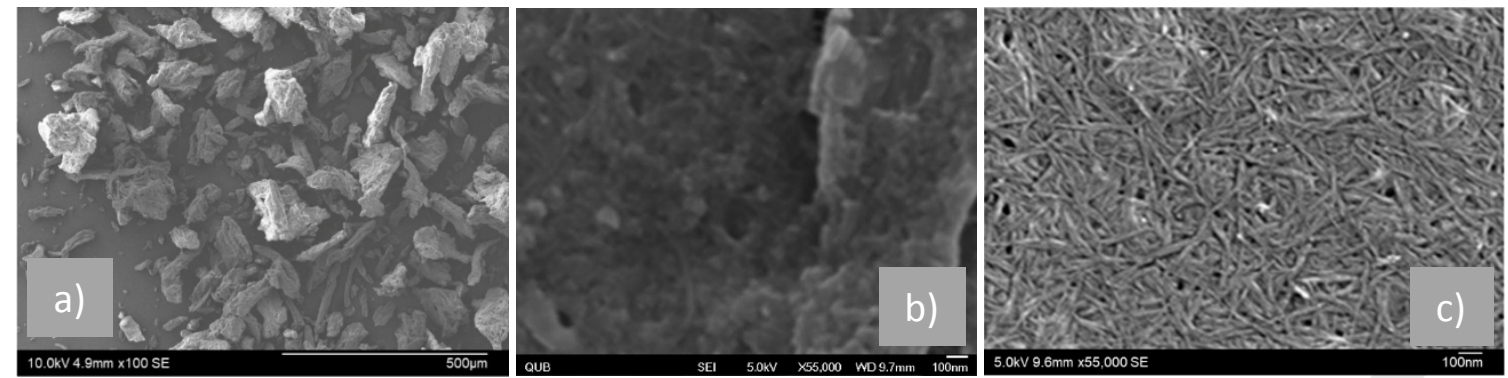

Figure 1: Scanning electron microscopy images of a) MCC particles (x100), b) close-up of individual MCC particle (x55,000), c) CNC after ultrasonication (x55,000).

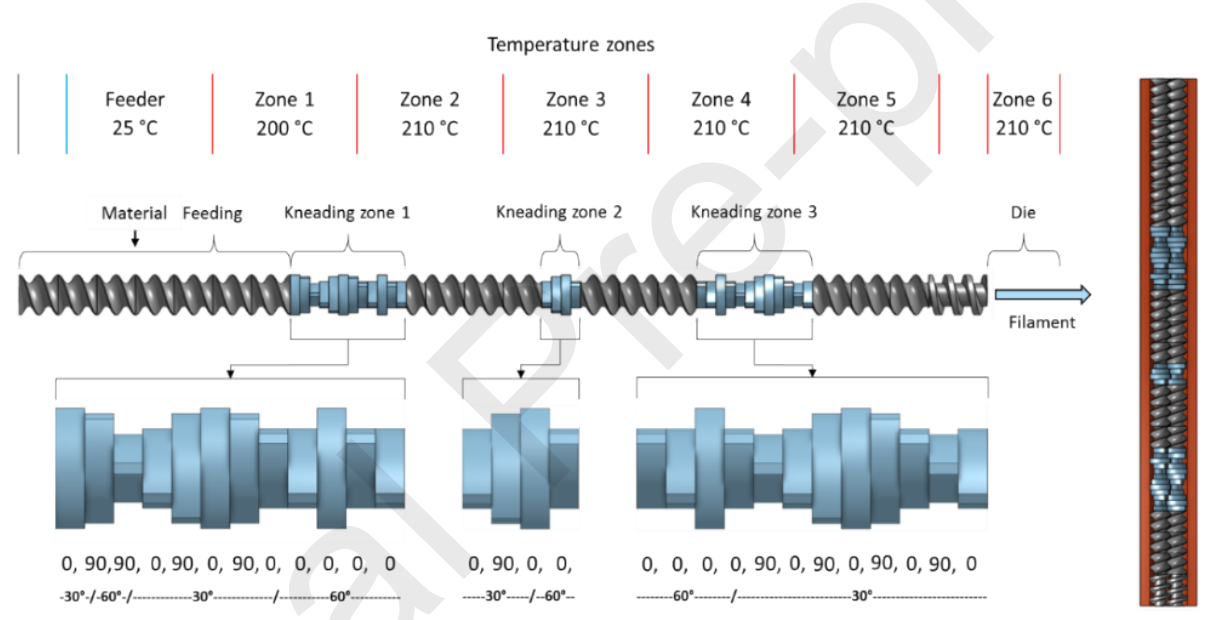

Figure 2: Screw design 1; low-shear screw configuration. Kneading sections are augmented to highlight the arrangements of kneading blocks leading to low shear forces. Co-rotating twin-screw set-up for screw design 1 on the right-hand side. 


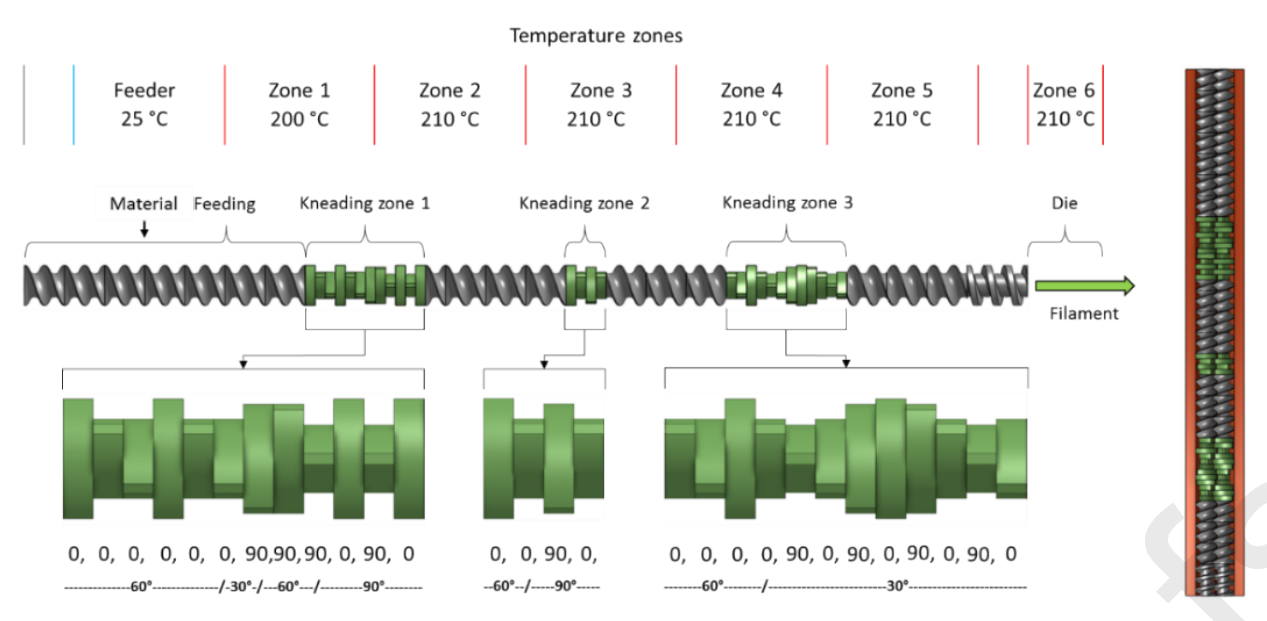

Figure 3: Screw design 2; high-shear screw configuration. Kneading sections are augmented to highlight the arrangements of kneading blocks leading to high shear forces. Co-rotating twin-screw set-up for screw design 2 on the right-hand side.
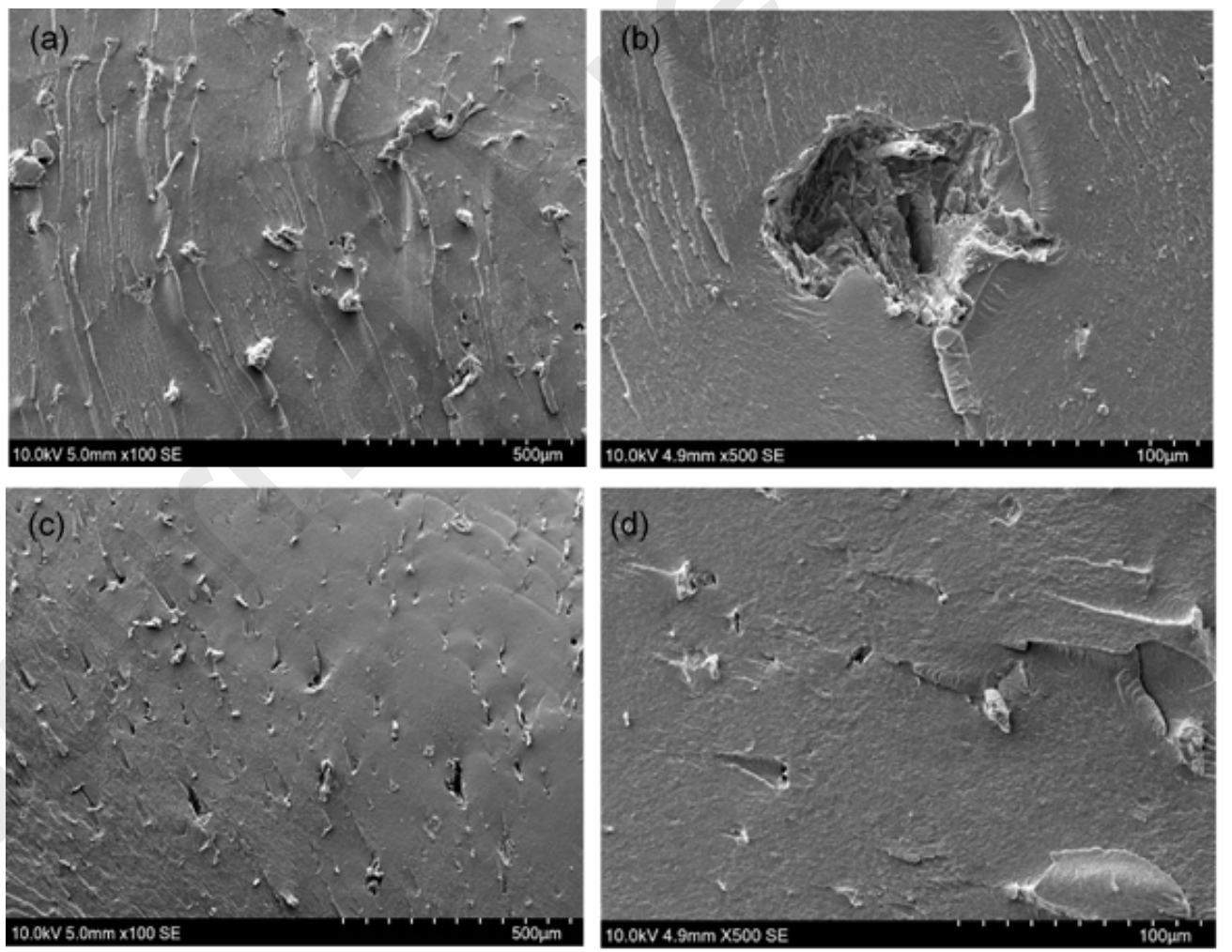

Figure 4: Dispersion characterization for MCC (5wt.\%) - EVOH composites for; a) low-shear (x100), b) low-shear (x500), c) high-shear (x100), d) high-shear (x500). 

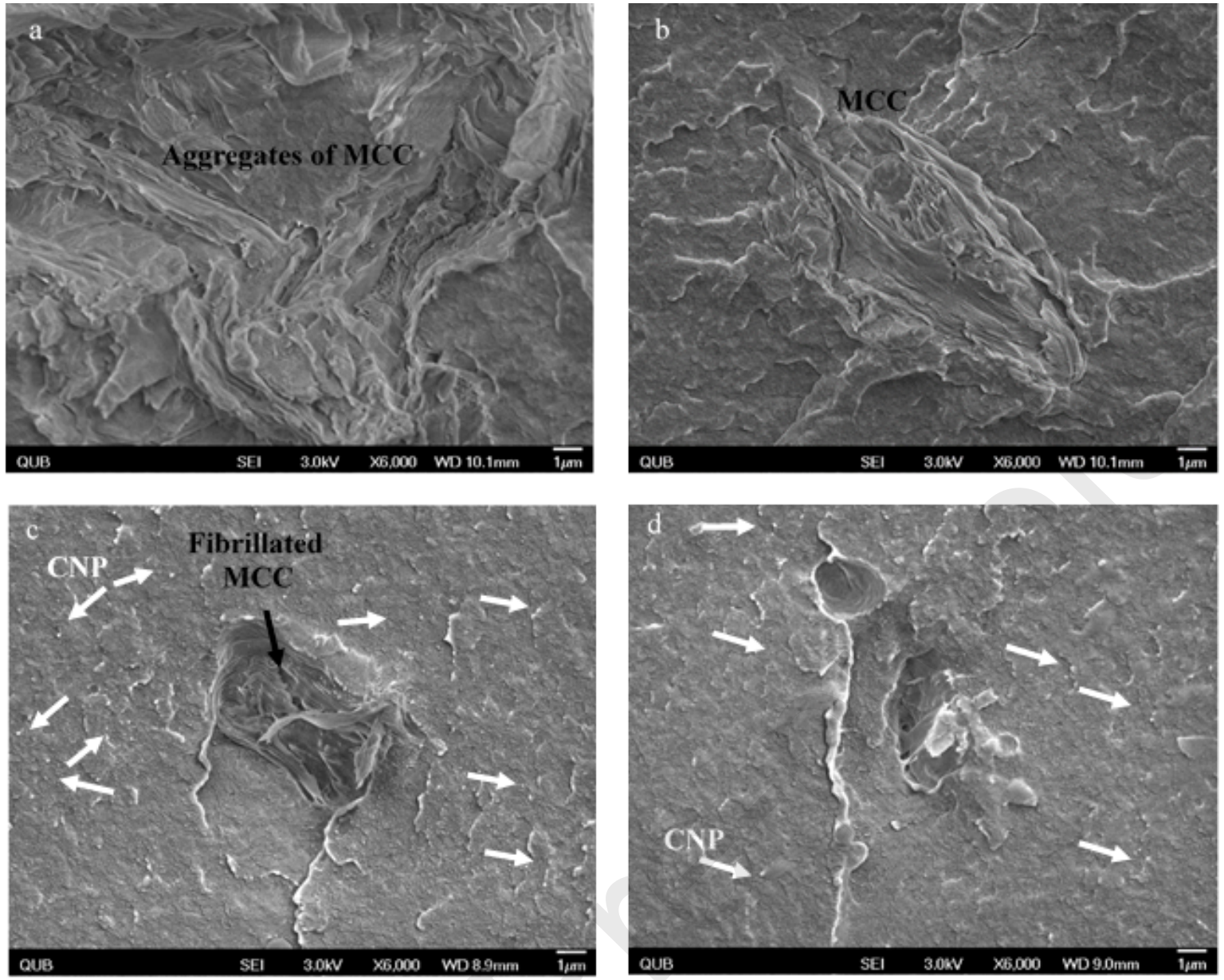

Figure 5: Fracture surfaces of EVOH/MCC composites containing 5 wt. $\%$ of $\mathrm{MCC}, \mathrm{a} \& \mathrm{~b}$ ) after LS processing (x6000), c \& d) after HS processing (x6000).
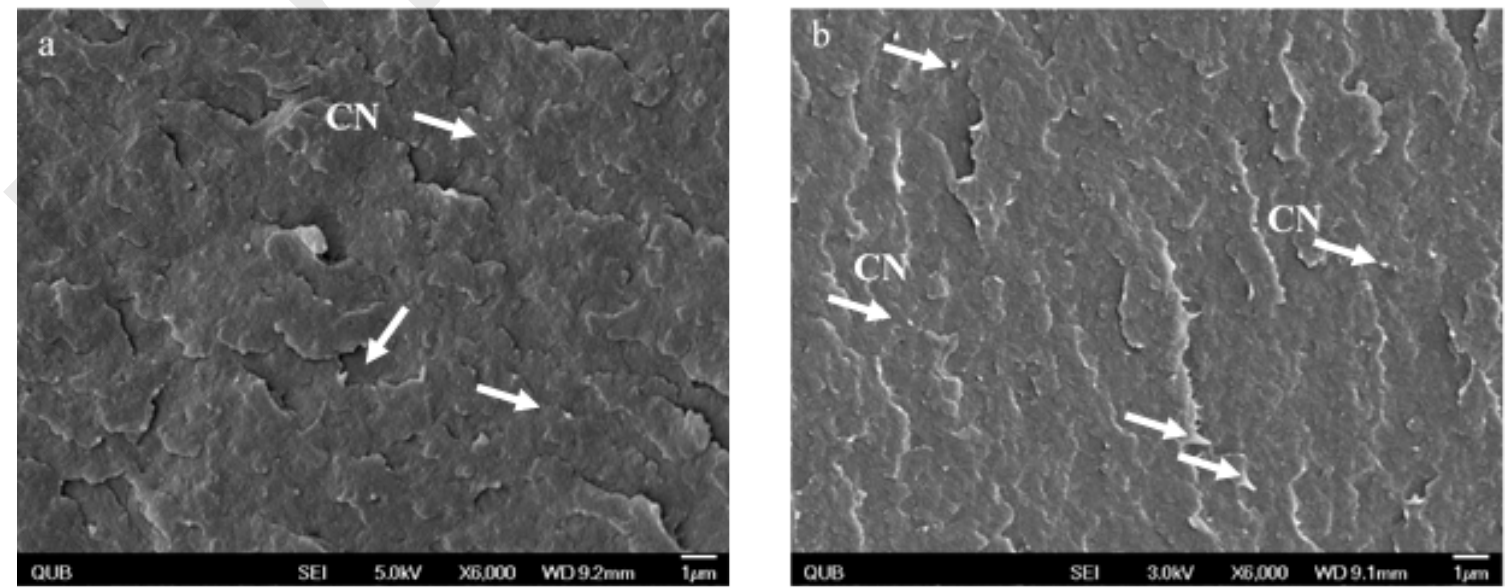

Figure 6: Fracture surfaces of EVOH/CNC composites containing 5 wt. $\%$ of $\mathrm{CNC}$, a) after LS processing (x6000), b) after HS processing (x6000). 

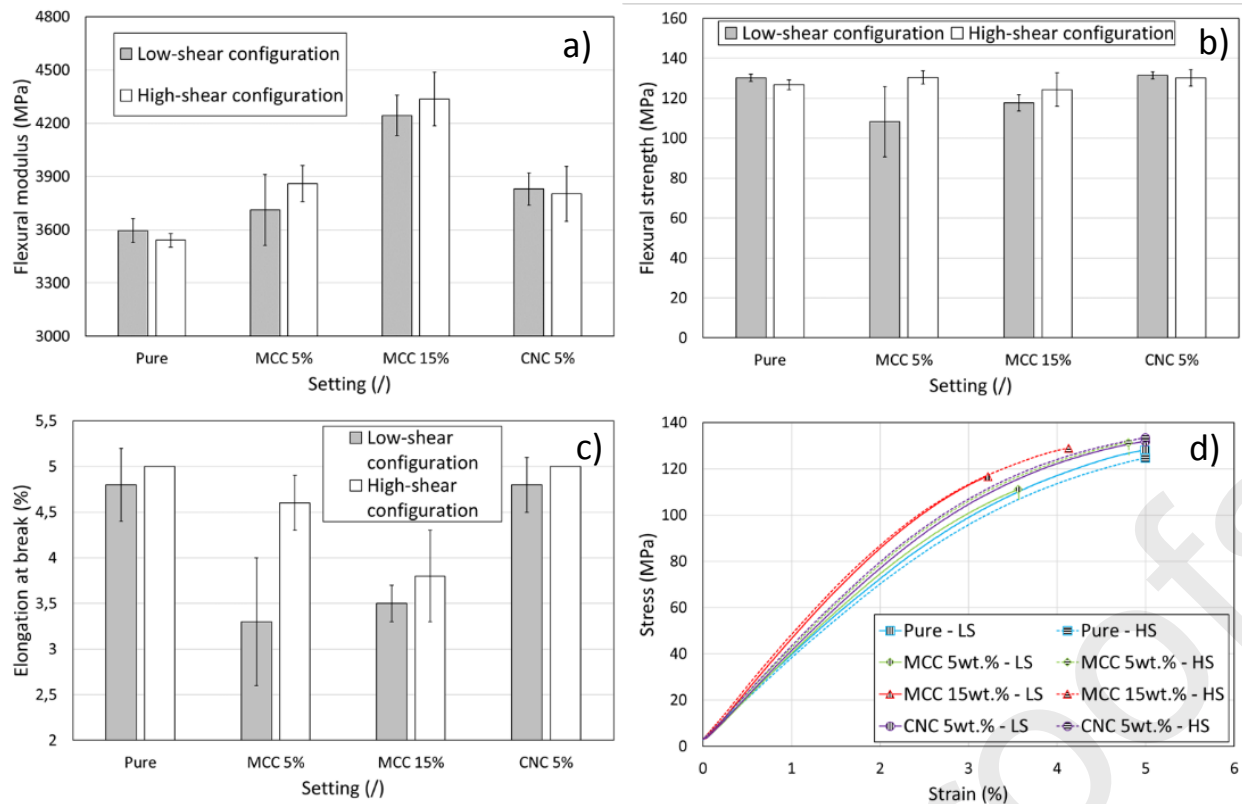

Figure 7: Influence of screw configuration on the flexural properties, a) flexural modulus, b) flexural strength, c) strain-at-break, d) representative stress-strain curves
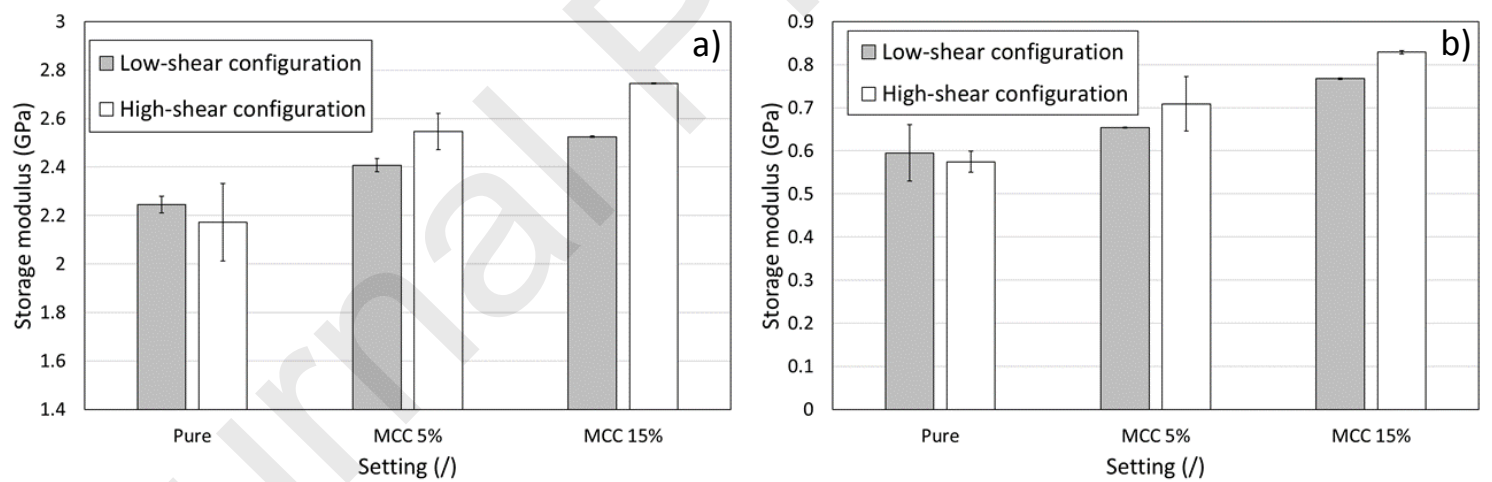

Figure 8: Storage modulus of EVOH and EVOH/MCC composites at different temperatures,

a) $30^{\circ} \mathrm{C}$, b) $110^{\circ} \mathrm{C}$. 


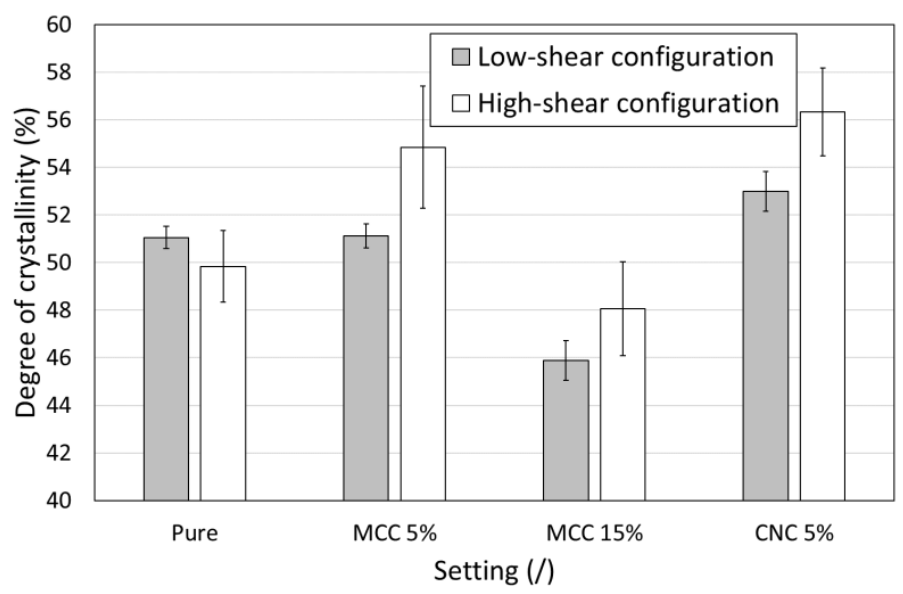

Figure 9: Degree of crystallinity for all settings calculated from the melt enthalpy of the melting peak in the second heating run. 